\title{
Effect of sub-chronic exposure to cigarette smoke, electronic cigarette and waterpipe on human lung epithelial barrier function
}

\author{
Baishakhi Ghosh ${ }^{1 \dagger}$, Hermes Reyes-Caballero ${ }^{1 * \dagger} \mathbb{D}$, Sevcan Gül Akgün-Ölmez ${ }^{2,3}$, Kristine Nishida ${ }^{4}$, \\ Lakshmana Chandrala ${ }^{5}$, Lena Smirnova ${ }^{2}$, Shyam Biswal ${ }^{1 *}$ and Venkataramana K. Sidhaye ${ }^{1,4^{*}}$
}

\begin{abstract}
Background: Taking into consideration a recent surge of a lung injury condition associated with electronic cigarette use, we devised an in vitro model of sub-chronic exposure of human bronchial epithelial cells (HBECs) in air-liquid interface, to determine deterioration of epithelial cell barrier from sub-chronic exposure to cigarette smoke (CS), e-cigarette aerosol (EC), and tobacco waterpipe exposures (TW).

Methods: Products analyzed include commercially available e-liquid, with $0 \%$ or $1.2 \%$ concentration of nicotine, tobacco blend (shisha), and reference-grade cigarette (3R4F). In one set of experiments, HBECs were exposed to EC ( 0 and 1.2\%), CS or control air for 10 days using 1 cigarette/day. In the second set of experiments, exposure of pseudostratified primary epithelial tissue to TW or control air exposure was performed 1-h/day, every other day, until 3 exposures were performed. After 16-18 h of last exposure, we investigated barrier function/structural integrity of the epithelial monolayer with fluorescein isothiocyanate-dextran flux assay (FITC-Dextran), measurements of trans-electrical epithelial resistance (TEER), assessment of the percentage of moving cilia, cilia beat frequency (CBF), cell motion, and quantification of E-cadherin gene expression by reverse-transcription quantitative polymerase chain reaction (RT-qPCR).

Results: When compared to air control, CS increased fluorescence (FITC-Dextran assay) by 5.6 times, whereby CS and EC (1.2\%) reduced TEER to 49 and 60\% respectively. CS and EC (1.2\%) exposure reduced CBF to 62 and 59\%, and cilia moving to 47 and $52 \%$, respectively, when compared to control air. CS and EC (1.2\%) increased cell velocity compared to air control by 2.5 and 2.6 times, respectively. The expression of E-cadherin reduced to $39 \%$ of control air levels by CS exposure shows an insight into a plausible molecular mechanism. Altogether, EC (0\%) and TW exposures resulted in more moderate decreases in epithelial integrity, while EC (1.2\%) substantially decreased airway epithelial barrier function comparable with CS exposure.

(Continued on next page)
\end{abstract}

\footnotetext{
*Correspondence: hreyesca@gmail.com; sbiswaljh@gmail.com;

vsidhay1@jhmi.edu

${ }^{\dagger}$ Baishakhi Ghosh and Hermes Reyes-Caballero contributed equally to this

work.

${ }^{1}$ Department of Environmental Health and Engineering, Johns Hopkins

Bloomberg School of Public Health, Baltimore, MD, USA

Full list of author information is available at the end of the article
}

(c) The Author(s). 2020 Open Access This article is licensed under a Creative Commons Attribution 4.0 International License, which permits use, sharing, adaptation, distribution and reproduction in any medium or format, as long as you give appropriate credit to the original author(s) and the source, provide a link to the Creative Commons licence, and indicate if changes were made. The images or other third party material in this article are included in the article's Creative Commons licence, unless indicated otherwise in a credit line to the material. If material is not included in the article's Creative Commons licence and your intended use is not permitted by statutory regulation or exceeds the permitted use, you will need to obtain permission directly from the copyright holder. To view a copy of this licence, visit http://creativecommons.org/licenses/by/4.0/. The Creative Commons Public Domain Dedication waiver (http://creativecommons.org/publicdomain/zero/1.0/) applies to the data made available in this article, unless otherwise stated in a credit line to the data. 
(Continued from previous page)

Conclusions: The results support a toxic effect of sub-chronic exposure to EC (1.2\%) as evident by disruption of the bronchial epithelial cell barrier integrity, whereas further research is needed to address the molecular mechanism of this observation as well as TW and EC (0\%) toxicity in chronic exposures.

Keywords: E-cigarette, Cigarette, Nicotine, E-cadherin, Waterpipe, Tobacco, Cilia

\section{Background}

Personal devices that deliver aerosolized nicotine for recreational purpose, known as Electronic Nicotine Delivery Systems or electronic cigarettes (EC) use an electric heating element to vaporize a liquid mixture (e-liquid) to produce an aerosol. Therefore, many potential harmful constituents from the combustion of tobacco in cigarette smoke (CS) are absent in EC. Thus, EC are currently accepted as a healthier alternative to ordinary cigarettes [1]. While long-term effects of EC in people are not known, animal studies have demonstrated that there are toxic effects of EC [2,3], and in vitro studies have found some dysregulation in bronchial and lung epithelial cells, lung fibroblast, and alveolar macrophages [2].

Tobacco smoking is the primary risk factor of chronic obstructive pulmonary disease (COPD) development. COPD is a progressive illness caused by chronic lung injury, with clinical manifestations that can include bronchitis, airway reactivity, and emphysema [4]. Considering the increased incidence of e-cigarette or vaping product use-associated lung injury, the evaluation of the biological activity of EC aerosol in in vitro models has become a top priority [5]. Hence, we studied the effects of sub-chronic EC aerosol exposure on human bronchial epithelial function in an in vitro air-liquid interface model in comparison to CS, and tobacco waterpipe (TW) exposures, in similar conditions. As the lining of the respiratory tract, the epithelia form a physical barrier that effectively prevents inhaled environmental insults from damaging the sub-epithelial layers [6]. Not surprisingly, we and other researchers have demonstrated that CS exposure disrupts the connectivity between adjacent cells in the lung epithelium interfering with the function of cell-cell adhesion proteins, often members of the cadherin family of adhesion molecules [7-12]. Additionally, there is evidence of detrimental effects of CS exposure on the mucociliary clearance of entrapped particulates in the lung track, which is mediated by the synchronous beats of protruding organelles in ciliated cells from the lung epithelium $[13,14]$. Thus, our study informs on the effects of EC aerosol exposure on the lung epithelial function and a synergistic effect of nicotine in the eliquid. We demonstrated that EC aerosol, as well as CS and TW can distinctly harm the lung epithelial barrier, an observation that in the context of previous experiments, supports a correlation with the time of exposure.
Therefore, our report emphasizes the need for more studies of long-term health and harmful consequences that may affect users of ECs.

\section{Methods \\ Study design}

We investigated the epithelial cell barrier function deterioration by exposure to CS, EC ( $0 \%$ of nicotine) and EC (1.2\% of nicotine), as well as the effect of TW. We devised an in vitro model of cell growth at the air-liquid interface for longer exposures. Human bronchial epithelial cells (HBECs) in an air-liquid interface were exposed to a reference CS, and a commercial EC with either 0 or $1.2 \%$ nicotine, compared to a clean air control using a normal puffing regime (CORESTA). The HBECs samples were acquired from a commercial entity as primary lung cells isolated from two donors (Table 1, donor 1 and 2), and we uses 3-5 HBECs samples for each of the CS, EC or air only (control group) exposures (Table 1). Differentiated HBECs were exposed to 10 puffs of EC aerosols, CS or air control each day for 10 days. 18 to 24 $\mathrm{h}$ recovery periods followed each exposure. Epithelial monolayer function was monitored by FITC-Dextran, TEER, CBF (\% of pixels), and cell velocity $16-18 \mathrm{~h}$ after the last exposure. To measure the effect on transcript levels, RT-qPCR was performed. An additional set of experiments evaluated the effects of exposure to TW in the epithelial cell barrier function using pseudostratified

Table 1 Number of samples used per donor in each experimental group

\begin{tabular}{|c|c|c|c|}
\hline \multirow{2}{*}{$\begin{array}{l}\text { Group } \\
\text { Experiment }\end{array}$} & \multicolumn{2}{|c|}{$\mathrm{CS}$ and $\mathrm{EC}$} & \multirow{2}{*}{$\begin{array}{l}\text { TW } \\
\text { Donor } 3\end{array}$} \\
\hline & Donor 1 & Donor 2 & \\
\hline FITC-Dextran & 2 & 1 & N.d. \\
\hline TEER & 3 & 2 & 3 \\
\hline CBF and \%Pixels & 3 & 2 & 3 \\
\hline Cell velocity & 3 & 2 & N.d. \\
\hline RT-qPCR & 2 & 1 & 3 \\
\hline Age & 50 & 40 & 59 \\
\hline Sex & Male & Female & Female \\
\hline Health status & Healthy & Healthy & Healthy \\
\hline
\end{tabular}

We did not collect cells directly; demographic data are provided by Epithelix and MatTek (details in the Methods section), and presented for informative purposes. The number of samples and origin (donor number) in the control groups is matched to information reported in Table 1. N.d, not determined 
primary epithelial tissue from donor 3 (MucilAir, Table 1) obtained from a commercial outlet. TW smoke was generated by combustion of commercial tobacco blend (shisha) using the modified Beirut regimen [15]. Three samples from donor 3 in an air-liquid interface were exposed for $1 \mathrm{~h}$ every other day until three exposures were performed. To each TW exposure preceded an exposure to the control group (exposed to air only) with a matching number of samples. Every other day refers to a recovery period of $48 \mathrm{~h}$ that followed each exposure. Monolayer barrier integrity was evaluated using TEER, CBF (\% of pixels), 12-16 h after the last exposure and RT-qPCR was performed following the exposure. The average of 3 to 5 insert samples per experiment allowed us to observe a significant difference among experimental groups using non-parametric statistical analysis. The number of samples analyzed per group is similar to those reported in previous studies $[16,17]$.

\section{Cells}

The source of HBECs is MatTek (USA) for EC and CS experiments, and differentiated MucilAir pseudostratified primary epithelial tissue from Epithelix (Switzerland) for TW experiments. The demographic information of the donors, the number of samples for each experiment and each donor are shown in Table 1. Amplification of the cryopreserved HBECs was performed on a collagencoated flask with PneumaCult-Ex Plus medium at $37^{\circ} \mathrm{C}$, and $5 \% \mathrm{CO}_{2}$. Passage of cells occurred at 80 to $90 \%$ confluency. The density of HBECs was 150,000 cells/well, and 400,000 cells/well for $6.5 \mathrm{~mm}$ and $12 \mathrm{~mm}$ transwells, respectively, on collagen-coated $0.4 \mu \mathrm{m}$ pore polyethylene terephthalate, clear membrane transwells with apical and basolateral PneumaCult-Ex Plus medium. HBECs were differentiated for 4 to 6 weeks into pseudostratified epithelia at the air-liquid interface after reaching $100 \%$ confluency with PneumaCult-ALI at $37{ }^{\circ} \mathrm{C}$ and $5 \% \mathrm{CO}_{2}$. MucilAir cells were incubated in identical conditions using MucilAir media.

\section{Smoke and vapor generation and exposure}

EC was generated from a commercial V2 vaping pen Pro Series 3-in-1 vaporizer (power $5.19 \mathrm{~W}$, resistance $3.3 \Omega$ ) [18] containing a classic tobacco flavor e-liquid cartridge with $0 \%$ or $1.2 \%$ nicotine (V2), whereas whole CS from reference-grade 3R4F cigarette (Kentucky). The EC and CS exposures were performed according to the Cooperation Center for Scientific Research Relative to Tobacco (CORESTA) Recommended Method No. 81 (CRM No 81), which consist of a square-wave puff profile of $55 \mathrm{~mL}$ puff volume, $3 \mathrm{~s}$ duration, and $30 \mathrm{~s}$ puff interval [16]. A Masterflex peristaltic pump puffed whole smoke into the Vitrocell (Germany) exposure chamber, whereas the control inserts were exposed to humidified air (control air) in the exposure system using the same profile. In a different set of experiments, we used the modified Beirut profile for TW smoke generation [15]. Briefly, a laboratory-grade waterpipe (Batelle) burned 12 to $13 \mathrm{~g}$ of shisha (Exotic Pirate's Cave, Starbuzz) with a lit $40 \mathrm{~mm}$ charcoal placed on top of an aluminum foil (10 min pre-heated) covering the TW head, and smoke generated using a puffing regimen as follow: $530 \mathrm{~mL}$ puff, $3 \mathrm{~s}$ duration, puff interval $17 \mathrm{~s}$. The charcoal was replaced after $30 \mathrm{~min}$. We omitted the TW head for the control air exposures. The exposure system received whole TW smoke or control air (set to $6 \mathrm{~L} / \mathrm{min}$ with an on-line manifold), and constant humidified filtered air $(1 \mathrm{~L} / \mathrm{min})$, while a vacuum input smoke constantly into the exposure chamber at $5 \mathrm{~mL} / \mathrm{min}$.

\section{Permeability measurement}

Permeability was assessed by fluorescein isothiocyanatedextran flux assay (FITC-Dextran flux assay), and transelectrical epithelial resistance (TEER), as described previously [11] 16 to $18 \mathrm{~h}$ post-exposure. For TW exposures, TEER was determined after the second exposure only due to technical issues with TEER measurement of control samples after the third exposure. We did not measure FITC-Dextran flux assay in cells exposed to TW.

\section{Ciliary beat frequency (CBF)}

The plates containing the pseudostratified epithelia were incubated at $37{ }^{\circ} \mathrm{C}$ with $5 \% \mathrm{CO}_{2}$ in the 3iMarianis Spinning-Disk Confocal. High-speed time-lapse videos were taken at $32 \mathrm{X}$ air at $100 \mathrm{~Hz}$ with a total of 250 frames using a scientific CMOS camera. Five areas imaged per insert. A Matlab (R2018b) script (validated against SAVA) [19] was used to determine average CBF per video, to generate a heat map indicating $\mathrm{CBF}$, and to determine percent pixels moving.

\section{Cell velocity}

Utilizing a microscopy methodology recently developed in our laboratory, we captured time-lapse videos of the epithelial cell monolayer for $2 \mathrm{~h}$ following exposure and computed the average velocity for the area. Briefly, on cells exposed to EC or CS, time-lapse videos are taken at phase contrast using the $32 \mathrm{X}$ dry objective with one frame taken every $5 \mathrm{~min}$ for $2 \mathrm{~h}$. We did not measure cell velocity in cells exposed to TW. Cell migration was quantified by performing Particle Image Velocimetry (PIVlab) on Matlab using multi-pass cross-correlation analysis with decreasing interrogation window size on image pairs to obtain the spatial velocity field as described previously [20].

\section{CDH1 expression}

Total RNA was isolated from cultured primary bronchial epithelial cells and purified using a column kit 
supplemented with the Proteinase $\mathrm{K}$ and RNase-Free Dnase Set, and cDNA of $1000 \mathrm{ng} \cdot \mu \mathrm{L}^{-1}$ was obtained using a cDNA Reverse Transcription Kit (Qiagen). In the case of MucilAir cultures exposed to TW, total RNA was isolated with Tryzol and Zymo Clean and Concentrator Kit. The absence of DNA contamination was verified by excluding the reverse transcriptase from subsequent PCR reactions. cDNA was subjected to PCR using the SYBRGreen PCR Master Mix to amplify $C D H 1$ (E-cadherin), and the housekeeping gene GADPH (Glyceraldehyde-3-phosphate dehydrogenase) mRNAs using primers shown in Table 2. GADPH is a housekeeping gene in epithelial tissues reliable for $C D H 1$ quantification [21-24]. The program in the C1000-PCR thermocycler was $94{ }^{\circ} \mathrm{C}, 15 \mathrm{~min}$, followed by 45 cycles $\left(94{ }^{\circ} \mathrm{C}\right.$, $35 \mathrm{~s} ; 60^{\circ} \mathrm{C}, 1 \mathrm{~min} ; 72^{\circ} \mathrm{C}, 1 \mathrm{~min} 15 \mathrm{~s}$ ) ending in $72^{\circ} \mathrm{C}, 2$ min. Based on the comparative $\mathrm{C} t$ method, transcript expression levels were calculated. The amplified products were visualized by transilluminator in 3\% agarose gel electrophoresis, stained with ethidium bromide.

\section{Statistical analysis}

Prism v7.0 (GraphPad) was used for analysis. As shown in figures, the $p$-values were considered statistically significant $(p<0.05)$ according to a non-parametric hypothesis test. We applied a Kruskall-Wallis rank-sum test followed by Dunn's multiple comparison test in CS and EC experiments. To compare two data sets in TW, we used a Kolmogorov-Smirnov test.

\section{Results}

Increased permeability in epithelial cell monolayer exposed to electronic cigarette with nicotine and cigarette smoke

Fig. 1a shows that exposure of HBECs cells to CS significantly increased fluorescence levels, reflecting the loss of barrier function as monolayer permeability increases in the basal media by six-fold compared to the air-exposed monolayer of epithelial cells. Importantly, the monolayer of epithelial cells exposed to 0\% nicotine EC aerosol showed a modest increase in permeability, that doubled in cells exposed to EC aerosol with 1.2\% nicotine, albeit not significant and $\sim 33 \%$ less permeable than monolayers exposed to CS.

Figure $1 \mathrm{~b}$ indicates a trend towards a decrease in TEER of a cell monolayer exposed to EC aerosol with $0 \%$ nicotine, compared to control (air-exposed). The presence of nicotine in the aerosol caused a disruption that significantly decreases TEER by $\sim 40 \%$, similar to CS. In other set of experiments (Fig. 1c), we showed that in MucilAir cells exposed to TW, TEER dropped by $25 \%$ (nonsignificant) compared to baseline after the second exposure. Different basal permeabilities in MucilAir and HBECs hindered direct comparison of toxicological effects; however, EC $(0 \%)$ and TW tend to decrease TEER. Based on the above results, we demonstrated compromised integrity of the epithelial monolayer barrier due to CS and EC (1.2\%) but not EC (0\%), suggesting that nicotine plays a major role in this barrier disruption. While the effect is not as dramatic as that with conventional cigarettes, this could be a function of exposure time.

\section{Exposure to electronic cigarette aerosol with nicotine,} and cigarette smoke modulated ciliary beat frequency in an epithelial cell monolayer

We sought to determine if EC and TW aerosols alter ciliary function. Exposure of cells to EC aerosol resulted in a trend towards a decrease (nonsignificant) in CBF, (Fig. 2a and Additional file 1). While this decrease in CBS was seen without the addition of nicotine, it became significant in the presence of $1.2 \%$ nicotine similar to CS exposure. Interestingly, MucilAir cells exposed to TW tend to increase CBF, although nonsignificant. (Fig. 2c).

In addition to beat frequency, the number of beating cilia can also affect mucocilliary clearance; therefore, we quantified this by measuring the number of pixels that were moving in each visual field. We found that EC aerosol exposure tends to decrease pixel counts (nonsignificant), suggestive of fewer beating cilia in the cell monolayer compared to control air, that decreases significantly with $1.2 \%$ nicotine in the e-liquid similar to the level observed in cells exposed to CS (Fig. 2b). Furthermore, the unchanged pixel counts in cell monolayer exposed to TW were consistent with the aforesaid tendency to increased CBF (Fig. 2d). The results indicate that only aerosolized EC containing nicotine may decrease epithelial mucociliary clearance, but not those without nicotine.

\section{Increased cell velocity in epithelial cell monolayer exposed to cigarette smoke or electronic cigarette aerosol with nicotine}

Using micro-video technology, we capture the movement of cilia and its velocity. Figure 3 shows a significant increase in cell velocity after CS exposure. Furthermore,

Table 2 DNA primers (5'-3')

\begin{tabular}{llll}
\hline Gene & Forward & Reverse & Product (bp) \\
\hline CDH1 & CCCACCACGTACAAGGGTC & CTGGGGTATTGGGGGCATC & 94 \\
GAPDH & AACGGGAAGCTCACTGGCATG & TCCACCACCTGTTGCTGTAG & 304 \\
\hline
\end{tabular}




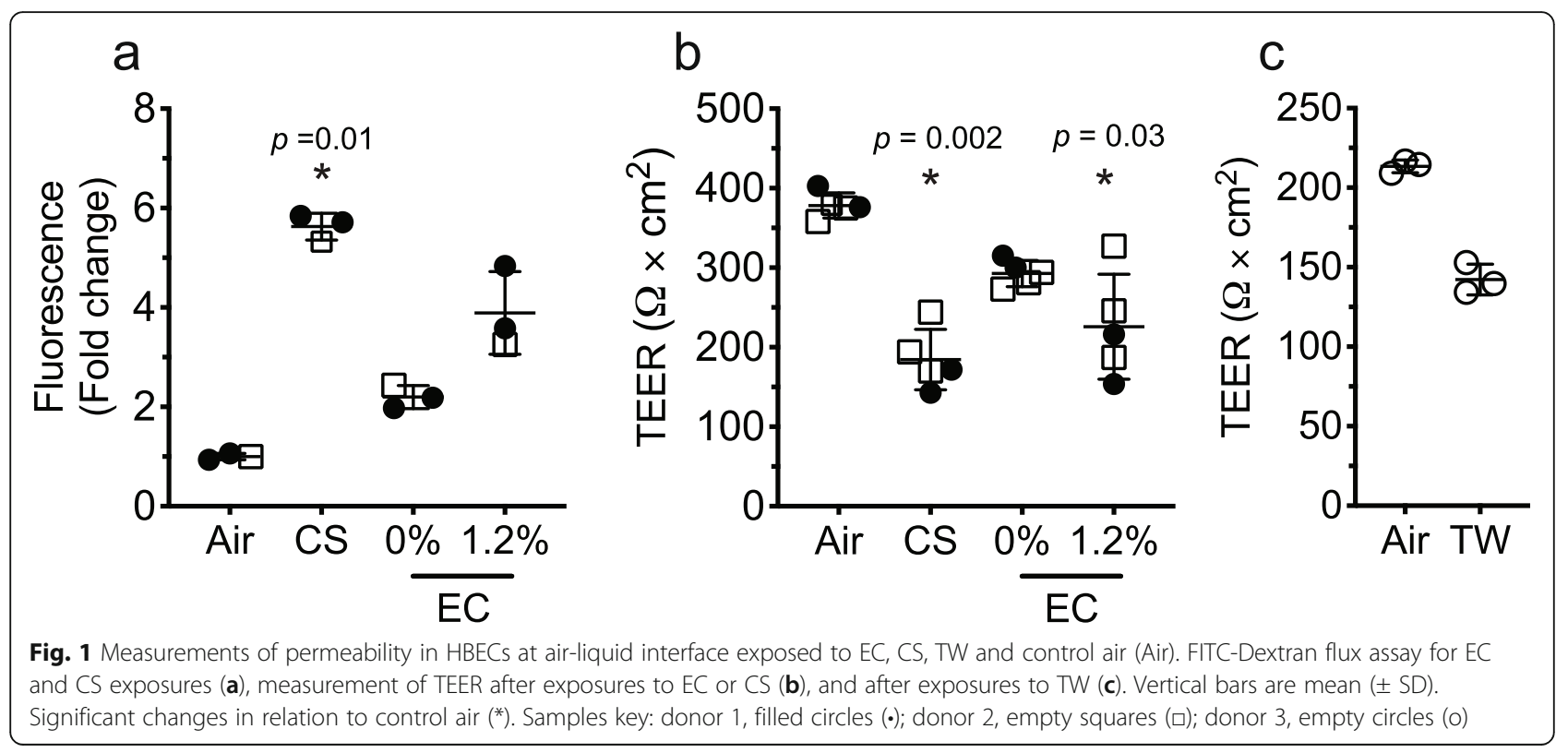

the EC exposure tends to increase cell velocity that became significant with $1.2 \%$ nicotine added, to a similar extend as the CS exposure. (Fig. 3 and Additional file 2).

\section{Exposure to cigarette smoke dismantled adherence junctions}

The exposure of epithelial cells to EC with and without nicotine or TW resulted in a modest decrease (nonsignificant) of $C D H 1$ transcript (which encodes E-cadherin) compared to the significant decrease $(39 \%)$ observed in cells exposed to CS (Fig. 4a, b). The decrease in CDH1 directly correlates with barrier disruption as described above occurring with CS exposure, followed by EC with nicotine. In all experiments, EC (0\%) and TW have shown the tendency of disruption, but the observations were not significant, plausible due to the small sample size.

\section{Discussion}

There is increasing recognition that CS can disrupt the epithelial barrier due to the toxicity of the mixture of chemicals acting through several molecular mechanisms that include MAPK (mitogen-activated protein kinase), TGF $\beta$ (transforming growth factor beta-1), and reactive oxygen species [25-29]. EC aerosol produced from eliquid (propylene-glycol and glycerol) and smoke from TW contain many of the same toxicants found in CS; therefore, it is not surprising that similar pathways may be activated by exposure to EC and TW [10,30-33]. For the determination of toxic effects, we used primary

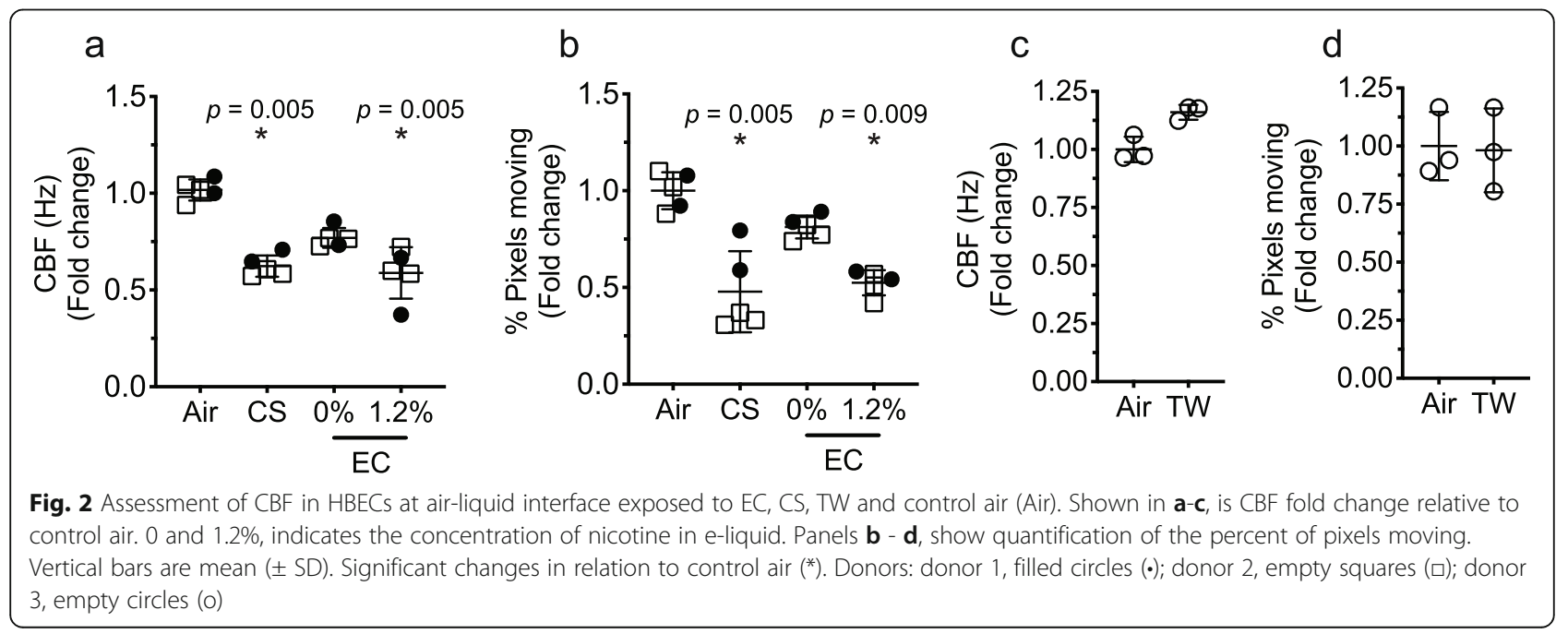




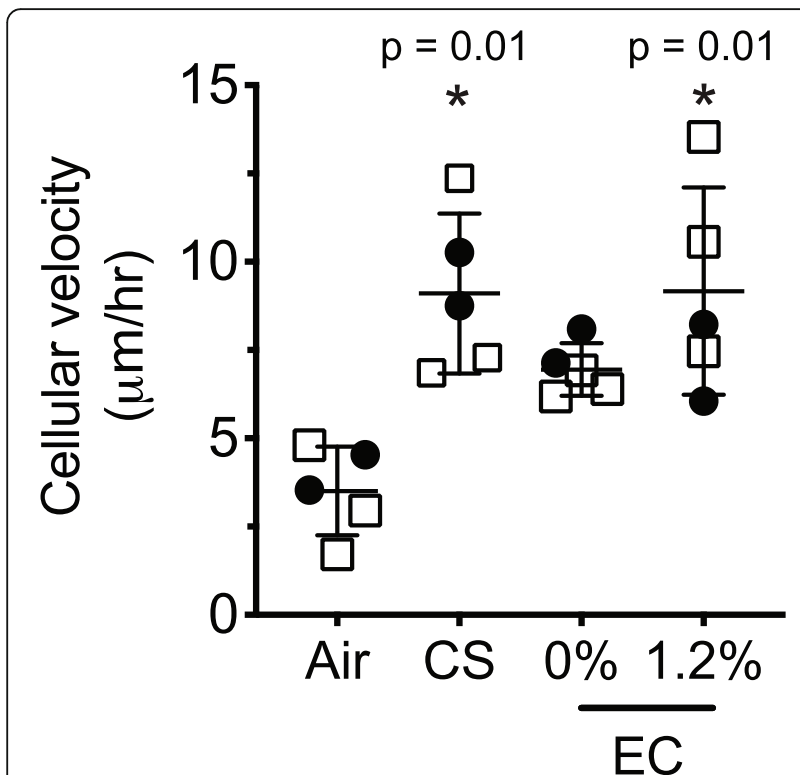

Fig. 3 Cell velocity analysis using time-lapse video of epithelial cell monolayer exposed to CS or EC aerosol. We did not measure cell motility in cells exposed to TW. Values show mean \pm SD. ${ }^{*}$, significant changes in relation to control air. Donors: donor 1, filled circles (•); donor 2, empty squares ( $\square$ ); donor 3, empty circles (o)

differentiated human lung epithelial cells as they replicate the human lung physiology well enough for assessments of health risks [34]. Two cell models were used for CS-EC and TW. Therefore, we minimized comparisons across the two sets of experiments to account for functional differences in cell barrier permeability observed in this study and as reported by other researchers [17]. The changes in fluorescence levels that resulted from CS exposure (FITC-Dextran assay decreased 5.6 times, and TEER decreased to 50\% compared to control air) are in line with the previously observed loss of permeability after CS exposure $[8,11]$. In the exposure to EC with or without nicotine, we observed a trend to decreased permeability with FITC-Dextran assay and when using TEER to measure barrier properties, the toxic effect of EC (1.2\%) became significant, decreasing permeability by $60 \%$ compared to air control. TEER measures the movement of ions across an electric gradient applied parallel to the monolayer, with a decreased resistance reflecting a loss of monolayer integrity [35]. A significant change of TEER in cells exposed to TW may be masked by a low number of samples. Nevertheless, our previous studies indicate that the permeability of epithelial monolayers increase only after repeated exposure to cigarettes, suggesting that disruption of permeability, as observed in this study, is in proportion to the length of the exposure $[11,16,36]$. Indeed, an absence of epithelial barrier disruption in in vitro models of very short exposures to EC has been reported [37]. In addition, flavors in the eliquid may positively modulate permeability as well, which was previously shown in cell lines exposed to EC [38]. In our exposure with EC tobacco flavor without nicotine we do see a tendency to a reduction in barrier integrity based on TEER measurements that is significant in the presence of nicotine. Furthermore, we demonstrated that the presence of nicotine in EC (1.2\%) deteriorates mucociliary clearance by decreasing CBF by $59 \%$ with respect to the control air. Mucociliary clearance mechanism is one of the critical protective functions of the epithelial monolayer that is performed by the rhythmic and directional beating of cilia on a

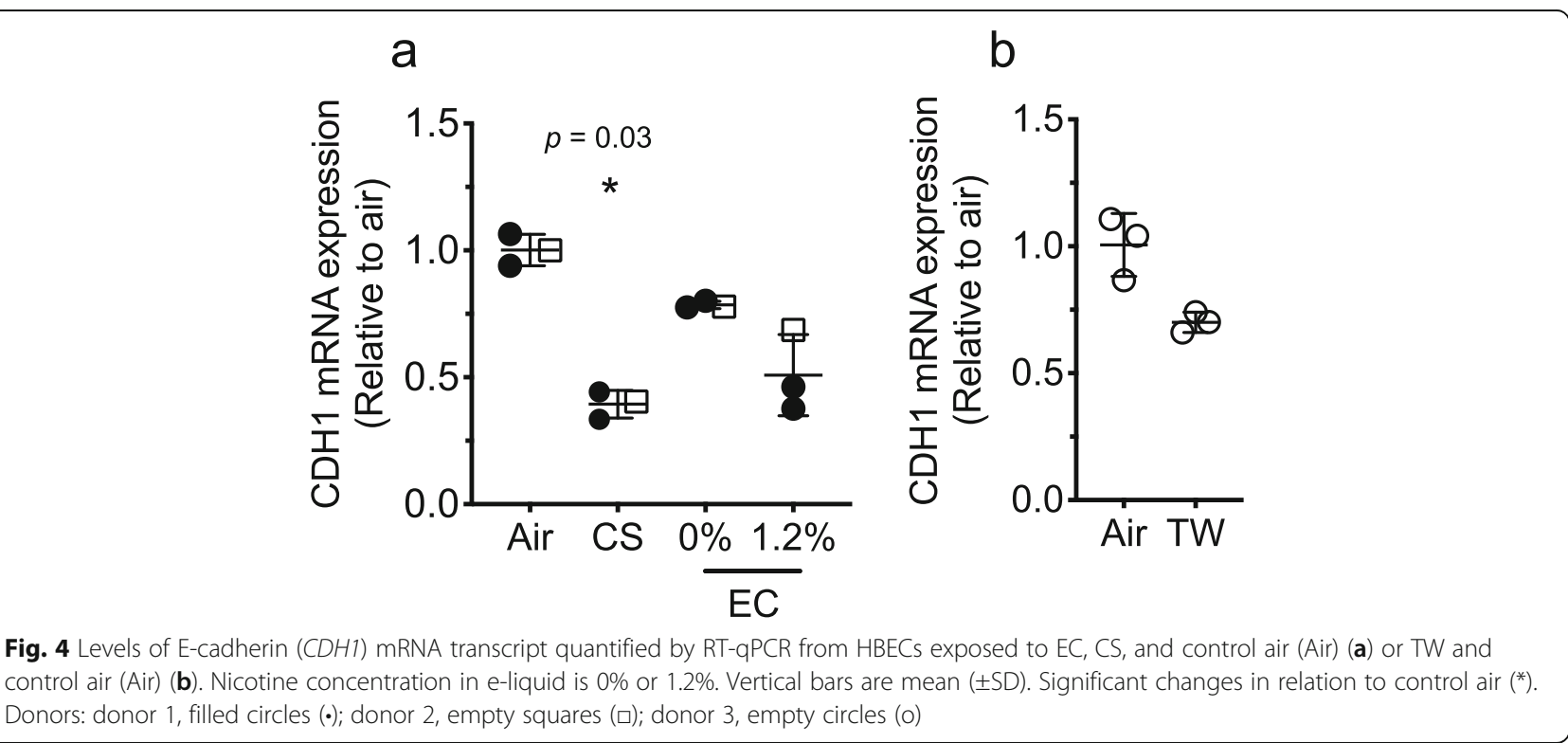


significant subpopulation of the monolayer [39]. Previous studies have shown shortening or loss of cilia, as well as decreases in CBF, are a direct result of the volatile organic compounds [40-44]. Whereas CS has a high concentration of volatile organic compounds, EC aerosols have concentrations that vary with the abundance of flavoring components and the glycerol:propylene-glycol ratio in the e-liquid [45-48]. Here, we show a significantly decreased $\mathrm{CBF}$ and pixel movement upon exposure to CS or EC (1.2\%) by 62 and $47 \%$, respectively. We and other researchers have shown that CS exposure leads to decreased CBF and number of cilia in epithelial cell monolayers that is in line with previous studies in which deteriorating effects of CS on ciliated cells were reported $[11,13,49]$; however, the results obtained from our chronic EC (1.2\%) exposure are novel. The plausible additive effect of nicotine in decreasing CBF, suggested in our experiment, is in striking contrast with recent report that showed nicotine exposure of cultured epithelial cells has no effect on CBF [50]. Therefore, based on our results, a synergistic effect of nicotine and additional components of EC such as flavors, as well as other components of EC, need to be tested specifically in settings of the aerosolized EC exposure. For example, nicotine showed an additive effect in decreased mucociliary clearance mechanism and other lung epithelial lesions in cells and in vivo experiments of EC exposures [51, 52].

We have identified specific trends in effect with TW, albeit with weak statistical power due to a small sample number (3 replicas) in the TW experiments. While this does hamper any comprehensive conclusions, we do believe that this in vitro model is ideal for sub-chronic exposures and can be adapted for chronic exposures of TW and other tobacco products in need of urgent toxicological assessment (e.g. EC) [53, 54]. We note that whereas a (nonsignificant) increase in CBF may be a distinct effect of TW in our study, is not unprecedented. We have recognized several instances of similar responses to CS in vitro [42, 55], ex-vivo [56, 57], and in vivo [58]. Moreover, we have previously shown that continuous monitoring of $\mathrm{CBF}$ in lung epithelial cells exposed to CS revealed temporal fluctuations, with the appearance of CBF curve inflections in cells, minutes and hours into the recovery time [20]. Thus, while it could be attributed to distinct components present in the TW smoke [59], it is also entirely plausible that chronic exposures to TW would cause decreases in CBF, similar to that seen with EC and CS. We are currently planning to test this in our laboratory.

We have previously demonstrated a 5 to 10 times increase in cellular velocity of epithelial cells exposed to CS compared to control [20], and here we showed evidence of 2.5 and 2.6 times increase after exposure to CS and EC (1.2\%), respectively. The underlying molecular mechanisms that control cell velocity after CS or EC (1.2\%) exposures are beyond the scope of this report, and it will be examined in the future, but this observation correlates with the loss of cell-cell adhesion proteins and altered actin-myosin contractility [11]. Nevertheless, accumulating evidence suggests that a decreased expression of the $C D H 1$ gene, the main component of adhesin junctions in lung epithelial cells, is a marker of the loss of barrier function in response to CS [60,61]. Here, we show that EC (1.2\%) tended to decrease $C D H 1$ expression, while CS decreased by $39 \%$ compare to the control air. Therefore, future work is needed to explore if exposure to EC (1.2\%) alike that of CS, impairs the stability of adherence junctions that are necessary to keep adequate cell-cell interactions in the lung epithelium.

\section{Conclusions}

We devised a sub-chronic exposure system to measure the toxic effects of EC and other tobacco products by monitoring cell barrier disruption. Our results, albeit with limited number of samples, support that subchronic exposure to EC with $1.2 \%$ nicotine may disrupt the airway epithelia, similar to CS. More research with larger number of donor samples is being planned for the future. While, in our experimental conditions, EC 0\% and TW caused less epithelial barrier disruption, future experiments need to address the toxicological significance of prolonged exposure and nicotine concentration as well as other components of these tobacco products as determinants of harmful effects. Specifically, for EC and TW, the addition of a variety of flavors needs to be addressed, as they are not proven safe when inhaled. Our system is adequate for future studies of chronic exposures that are required to understand the health effects of long-term users of EC and TW.

\section{Supplementary information}

Supplementary information accompanies this paper at https://doi.org/10. 1186/s12890-020-01255-y.

Additional file 1. Exposure of epithelial cell monolayer to EC or CS shows dysregulation of CBF. The heat map is an overlap of a single field of view of HBECs at ALI. Hz (Hertz). Panels: control air (a), EC aerosol with $0 \%$ nicotine (b), EC aerosol with $1.2 \%$ of nicotine (c), CS (d).

Additional file $\mathbf{2}$. Showed is the heat map analysis of a single image taken during recording time-lapse video of HBECs exposed to (left to right) control air, CS, EC (0\%) nicotine and EC (1.2\%) nicotine.

\section{Abbreviations}

CBF: Cilia beat frequency; COPD: Chronic obstructive pulmonary disease; CS: Cigarette smoke; EC: Electronic cigarettes; HBECs: Primary human bronchial epithelial cells; MAPK: Mitogen-activated protein kinase; TEER: Trans-electrical epithelial resistance; TGF $\beta$ : Transforming growth factor beta 1; TW: Tobacco waterpipe 


\section{Acknowledgments}

We acknowledge the technical advice from Dr. Marielle Brinkman in the use of the laboratory-grade tobacco-waterpipe (Batelle), at the College of Public Health, The Ohio State University.

\section{Authors' contributions}

$B G, K N$, and SGAO, executed all experiments, prepared figures and statistical validation; LC, contributed to cell motion experiment and analysis; LS, contributed to experimental design and implementation; HRC, contributed to the experimental design, implementation, data analysis, data collection, data interpretation and drafting the manuscript; VKS and SB, were the principal investigators, conceived the idea, led the study design and edited manuscript. All authors have read and approved the manuscript.

\section{Funding}

This work was supported by the National Institutes of Health under Award Number R01HL134149 (to SB and LS), 3U01ES026721-02S1 (to HRC), RO1HL124099 (to VKS, KN, and BG) and by the Scientific and Technological Research Council of Turkey, under Funding Program 2219 (to SGAO). The funding agencies had no role in writing of the manuscript, the study design, the collection, analysis, and interpretation of data.

\section{Availability of data and materials}

This published article and its supplementary information files include all data generated or analyzed during this study. Raw data is available upon submission of request to vsidhay1@jhmi.edu, hreyesca@gmail.com or sbiswaljh@gmail.com.

\section{Ethics approval and consent to participate}

Not applicable for being an in vitro study.

\section{Consent for publication}

Not applicable for being an in vitro study.

\section{Competing interests}

The authors declare no competing interest.

\section{Author details}

'Department of Environmental Health and Engineering, Johns Hopkins Bloomberg School of Public Health, Baltimore, MD, USA. ${ }^{2}$ Department of Environmental Health and Engineering, Center for Alternatives to Animal Testing, Johns Hopkins Bloomberg School of Public Health, Baltimore, MD, USA. ${ }^{3}$ Present Address: Department of Pharmaceutical Toxicology, Faculty of Pharmacy, Marmara University, Istanbul, Turkey. ${ }^{4}$ Division of Pulmonary and Critical Care Medicine, Johns Hopkins School of Medicine, Baltimore, MD, USA. ${ }^{5}$ Department of Mechanical Engineering, Johns Hopkins Whiting School of Engineering, Baltimore, MD, USA.

Received: 10 March 2020 Accepted: 5 August 2020

Published online: 12 August 2020

\section{References}

1. Hartung T. E-cigaretters - the ugly duckling of public health? Sci Am. 2016; 315(2):9.

2. Chen IL, Todd I, Fairclough LC. Immunological and pathological effects of electronic cigarettes. Basic Clin Pharmacol Toxicol. 2019;125(3):237-52.

3. Dinakar C, O'Connor GT. The health effects of electronic cigarettes. N Engl J Med. 2016;375(14):1372-81.

4. Thorley AJ, Tetley TD. Pulmonary epithelium, cigarette smoke, and chronic obstructive pulmonary disease. Int J Chron Obstruct Pulmon Dis. 2007;2(4): 409-28.

5. Hartung T. Can we wait for e-cigarrette trials? : Royal Society of Chemistry; 2016 [Available from: https://www.chemistryworld.com/opinion/can-wewait-for-e-cigarette-trials/1010325.article\#/. Accessed July 2020.

6. Wittekindt $\mathrm{OH}$. Tight junctions in pulmonary epithelia during lung inflammation. Pflugers Arch. 2017;469(1):135-47.

7. Garcia MA, Nelson WJ, Chavez N. Cell-cell junctions organize structural and signaling networks. Cold Spring Harb Perspect Biol. 2018;10(4):a029181.

8. Heijink IH, Brandenburg SM, Postma DS, van Oosterhout AJM. Cigarette smoke impairs airway epithelial barrier function and cell-cell contact recovery. Eur Respir J. 2012;39(2):419.
9. Amatngalim GD, Vieira RP, Meiners S, Bartel S. Novel insights into the effects of cigarette smoke on the airway epithelial surface-lessons learned at the European Respiratory Society international congress 2018 in Paris. J Thorac Dis. 2018;10(Suppl 25):S2977-S82.

10. Forteza RM, Casalino-Matsuda SM, Falcon NS, Valencia Gattas M, Monzon ME. Hyaluronan and layilin mediate loss of airway epithelial barrier function induced by cigarette smoke by decreasing E-cadherin. J Biol Chem. 2012; 287(50):42288-98.

11. Nishida K, Brune KA, Putcha N, Mandke P, O'Neal WK, Shade D, et al. Cigarette smoke disrupts monolayer integrity by altering epithelial cell-cell adhesion and cortical tension. Am. J. Physiol. Lung Cell. Mol. Physiol. 2017; 313(3):L581-191.

12. Tatsuta M, Kan-o K, Ishii Y, Yamamoto N, Ogawa T, Fukuyama S, et al. Effects of cigarette smoke on barrier function and tight junction proteins in the bronchial epithelium: protective role of cathelicidin LL-37. Respir Res. 2019; 20(1):251.

13. Aufderheide M, Scheffler S, Ito S, Ishikawa S, Emura M. Ciliatoxicity in human primary bronchiolar epithelial cells after repeated exposure at the air-liquid interface with native mainstream smoke of K3R4F cigarettes with and without charcoal filter. Exp Toxicol Pathol. 2015;67(7):407-11.

14. Au-Kuehn D, Au-Majeed S, Au-Guedj E, Au-Dulize R, Au-Baumer K, AuIskandar A, et al. Impact Assessment of Repeated Exposure of Organotypic 3D Bronchial and Nasal Tissue Culture Models to Whole Cigarette Smoke. J. Vis. Exp. 2015;(96):52325.

15. Reyes-Caballero H, Park B, Loube J, Sanchez I, Vinayachandran V, Choi Y, et al. Immune modulation by chronic exposure to waterpipe smoke and immediate-early gene regulation in murine lungs. Tob Control. 2020; 29(Suppl 2):S80

16. Czekala L, Simms L, Stevenson M, Tschierske N, Maione AG, Walele T. Toxicological comparison of cigarette smoke and e-cigarette aerosol using a 3D in vitro human respiratory model. Regul Toxicol Pharmacol. 2019;103: 314-24.

17. Furubayashi T, Inoue D, Nishiyama N, Tanaka A, Yutani R, Kimura S, et al. Comparison of Various Cell Lines and Three-Dimensional Mucociliary Tissue Model Systems to Estimate Drug Permeability Using an In Vitro Transport Study to Predict Nasal Drug Absorption in Rats. Pharmaceutics. 2020;12(1): 79.

18. Voos N, Kaiser L, Mahoney MC, Bradizza CM, Kozlowski LT, Benowitz NL, et al. Randomized within-subject trial to evaluate smokers' initial perceptions, subjective effects and nicotine delivery across six vaporized nicotine products. Addiction. 2019;114(7):1236-48.

19. Sisson JH, Stoner JA, Ammons BA, Wyatt TA. All-digital image capture and whole-field analysis of ciliary beat frequency. J Microsc. 2003;211(Pt 2):103-11.

20. Chandrala LD, Afshar-Mohajer N, Nishida K, Ronzhes Y, Sidhaye VK, Koehler $\mathrm{K}$, et al. A device for measuring the in-situ response of human bronchial epithelial cells to airborne environmental agents. Sci Rep. 2019;9(1):7263.

21. Barber RD, Harmer DW, Coleman RA, Clark BJ. GAPDH as a housekeeping gene: analysis of GAPDH mRNA expression in a panel of 72 human tissues. Physiol Genomics. 2005;21(3):389-95.

22. Rosivatz E, Becker I, Specht K, Fricke E, Luber B, Busch R, et al. Differential expression of the epithelial-mesenchymal transition regulators snail, SIP1, and twist in gastric cancer. Am J Pathol. 2002;161(5):1881-91.

23. Li Y, Liu G, Zhang J, Zhong X, He Z. Identification of key genes in human airway epithelial cells in response to respiratory pathogens using microarray analysis. BMC Microbiol. 2018;18(1):58.

24. Nishida K, Ghosh B, Chandrala L, Mahmud S, Chen S, Khosla AA, et al. Quantifying Epithelial Plasticity as a Platform to Reverse Epithelial Injury. bioRxiv. 2020;2020.01.14.906008.

25. Eapen MS, Sharma P, Gaikwad AV, Lu W, Myers S, Hansbro PM, et al. Epithelial-mesenchymal transition is driven by transcriptional and post transcriptional modulations in COPD: implications for disease progression and new therapeutics. Int. J. Chron. Obstruct. Pulmon. Dis. 2019;14:1603-10.

26. Aghapour M, Raee P, Moghaddam SJ, Hiemstra PS, Heijink IH. Airway epithelial barrier dysfunction in chronic obstructive pulmonary disease: role of cigarette smoke exposure. Am J Respir Cell Mol Biol. 2017;58(2):157-69.

27. Wong FH, AbuArish A, Matthes E, Turner MJ, Greene LE, Cloutier A, et al. Cigarette smoke activates CFTR through ROS-stimulated CAMP signaling in human bronchial epithelial cells. Am J Physiol Cell Physiol. 2018;314(1): C118-C34.

28. Dey T, Dutta P, Manna P, Kalita J, Boruah HPD, Buragohain AK, et al. Cigarette smoke compounds induce cellular redox imbalance, activate NF- 
kappaB, and increase TNF-alpha/CRP secretion: a possible pathway in the pathogenesis of COPD. Toxicol. Res. (Camb.). 2016:5(3):895-904.

29. Gindele JA, Kiechle T, Benediktus K, Birk G, Brendel M, Heinemann F, et al. Intermittent exposure to whole cigarette smoke alters the differentiation of primary small airway epithelial cells in the air-liquid interface culture. Sci Rep. 2020;10(1):6257.

30. Farsalinos KE, Gillman G. Carbonyl Emissions in E-cigarette Aerosol: A Systematic Review and Methodological Considerations. Front. Physiol. 2018; 8:1119.

31. Strongin RM. E-cigarette chemistry and analytical detection. Annu Rev Anal Chem. 2019;12(1):23-39.

32. Haddad C, Salman R, El-Hellani A, Talih S, Shihadeh A, Saliba NA. Reactive oxygen species emissions from supra- and sub-ohm electronic cigarettes. Anal Toxicol. 2019:43(1):45-50.

33. Nemmar A, Yuvaraju P, Beegam S, Ali BH. Short-term nose-only water-pipe (shisha) smoking exposure accelerates coagulation and causes cardiac inflammation and oxidative stress in mice. Cell Physiol Biochem. 2015;35(2): $829-40$

34. Li X. In vitro toxicity testing of cigarette smoke based on the air-liquid interface exposure: a review. Toxicol in Vitro. 2016;36:105-13.

35. Srinivasan B, Kolli AR, Esch MB, Abaci HE, Shuler ML, Hickman JJ. TEER measurement techniques for in vitro barrier model systems. J Lab Autom. 2015;20(2):107-26.

36. Fields W, Maione A, Keyser B, Bombick B. Characterization and application of the VITROCELL VC1 smoke exposure system and 3D EpiAirway models for toxicological and e-cigarette evaluations. Appl. In Vitro Toxicol. 2017;3(1):68-83.

37. Herr C, Tsitouras K, Niederstraßer J, Backes C, Beisswenger C, Dong L, et al. Cigarette smoke and electronic cigarettes differentially activate bronchial epithelial cells. Respir Res. 2020;21(1):67.

38. Muthumalage T, Lamb T, Friedman MR, Rahman I. E-cigarette flavored pods induce inflammation, epithelial barrier dysfunction, and DNA damage in lung epithelial cells and monocytes. Sci. Rep. 2019;9(1):19035.

39. Ghosh A, Boucher RC, Tarran R. Airway hydration and COPD. Cell Mol Life Sci. 2015;72(19):3637-52

40. Jang AS, Concel VJ, Bein K, Brant KA, Liu S, Pope-Varsalona H, et al. Endothelial dysfunction and claudin 5 regulation during acrolein-induced lung injury. Am J Respir Cell Mol Biol. 2011;44(4):483-90.

41. Comer DM, Elborn JS, Ennis M. Inflammatory and cytotoxic effects of acrolein, nicotine, acetylaldehyde and cigarette smoke extract on human nasal epithelial cells. BMC Pulm Med. 2014;14:32.

42. Xiong R, Wu Q, Muskhelishvili L, Davis K, Shemansky JM, Bryant M, et al. Evaluating mode of action of Acrolein toxicity in an in vitro human airway tissue model. Toxicol Sci. 2018;166(2):451-64.

43. Fló-Neyret C, Lorenzi-Filho G, Macchione M, Garcia MLB, Saldiva PHN. Effects of formaldehyde on the frog's mucociliary epithelium as a surrogate to evaluate air pollution effects on the respiratory epithelium. Braz J Med Biol Res. 2001;34:639-43.

44. Wyatt TA, Schmidt SC, Rennard SI, Tuma DJ, Sisson JH. Acetaldehyde-stimulated PKC activity in airway epithelial cells treated with smoke extract from normal and smokeless cigarettes. Proc Soc Exp Biol Med. 2000;225(1):91-7.

45. Lee M-S, LeBouf RF, Son Y-S, Koutrakis P, Christiani DC. Nicotine, aerosol particles, carbonyls and volatile organic compounds in tobacco- and menthol-flavored e-cigarettes. Environ Health. 2017;16(1):42.

46. Keith RJ, Fetterman JL, Orimoloye OA, Dardari Z, Lorkiewicz P, Hamburg NM, et al. Characterization of volatile organic compound (VOC) metabolites in cigarette smokers, electronic nicotine device users, dual users and nonusers of tobacco. Nicotine Tob Res. 2019;22(2):264-72.

47. Khlystov A, Samburova V. Flavoring compounds dominate toxic aldehyde production during E-cigarette Vaping. Environ Sci Technol. 2016;50(23): 13080-5.

48. Ooi BG, Dutta D, Kazipeta K, Chong NS. Influence of the E-cigarette emission profile by the ratio of glycerol to propylene glycol in E-liquid composition. ACS Omega. 2019;4(8):13338-48.

49. Simet SM, Sisson JH, Pavlik JA, DeVasure JM, Boyer C, Liu X, et al. Long-term cigarette smoke exposure in a mouse model of ciliated epithelial cell function. Am J Respir Cell Mol Biol. 2010;43(6):635-40.

50. Maouche K, Medjber K, Zahm JM, Delavoie F, Terryn C, Coraux C, et al. Contribution of alpha7 nicotinic receptor to airway epithelium dysfunction under nicotine exposure. Proc Natl Acad Sci U S A. 2013;110(10):4099-104.

51. Laube BL, Afshar-Mohajer N, Koehler K, Chen G, Lazarus P, Collaco JM, et al. Acute and chronic in vivo effects of exposure to nicotine and propylene glycol from an E-cigarette on mucociliary clearance in a murine model. Inhal Toxicol. 2017;29(5):197-205.

52. Garcia-Arcos I, Geraghty P, Baumlin N, Campos M, Dabo AJ, Jundi B, et al. Chronic electronic cigarette exposure in mice induces features of COPD in a nicotine-dependent manner. Thorax. 2016;71(12):1119.

53. Fowle JJR, Curren RD, Hartung T, Proctor C, Wilcox N. Twenty-first century in vitro toxicology testing methods and the assessment of e-cigarettes. Appl In Vitro Toxicol. 2017;3(1):3-9.

54. Hartung T. E-cigarettes and the need and opportunities for alternatives to animal testing. Altex. 2016;33(3):211-24.

55. Navarrette CR, Sisson JH, Nance E, Allen-Gipson D, Hanes J, Wyatt TA. Particulate matter in cigarette smoke increases Ciliary Axoneme beating through mechanical stimulation. J Aerosol Med Pulm Drug Deliv. 2012;25(3): 159-68.

56. Zhou H, Wang X, Brighton L, Hazucha M, Jaspers I, Carson JL. Increased nasal epithelial ciliary beat frequency associated with lifestyle tobacco smoke exposure. Inhal Toxicol. 2009;21(10):875-81.

57. Carson JL, Lu TS, Brighton L, Hazucha M, Jaspers I, Zhou H. Phenotypic and physiologic variability in nasal epithelium cultured from smokers and nonsmokers exposed to secondhand tobacco smoke. In Vitro Cell Dev Biol Anim. 2010;46(7):606-12.

58. Coote K, Nicholls A, Atherton HC, Sugar R, Danahay H. Mucociliary clearance is enhanced in rat models of cigarette smoke and lipopolysaccharideinduced lung disease. Exp Lung Res. 2004;30(1):59-71.

59. Brinkman MC, Teferra AA, Kassem NO, Kassem NOF. Effect of electric heating and ice added to the bowl on mainstream waterpipe semivolatile furan and other toxicant yields. Tob Control. 2020;29:5110-6.

60. Hou W, Hu S, Li C, Ma H, Wang Q, Meng G, et al. Cigarette smoke induced lung barrier dysfunction, EMT, and tissue remodeling: a possible link between COPD and lung cancer. Biomed. Res. Int. 2019.

61. Shaykhiev R, Otaki F, Bonsu P, Dang DT, Teater M, Strulovici-Barel Y, et al. Cigarette smoking reprograms apical junctional complex molecular architecture in the human airway epithelium in vivo. Cell Mol Life Sci. 2011; 68(5):877-92.

\section{Publisher's Note}

Springer Nature remains neutral with regard to jurisdictional claims in published maps and institutional affiliations.
Ready to submit your research? Choose BMC and benefit from:

- fast, convenient online submission

- thorough peer review by experienced researchers in your field

- rapid publication on acceptance

- support for research data, including large and complex data types

- gold Open Access which fosters wider collaboration and increased citations

- maximum visibility for your research: over $100 \mathrm{M}$ website views per year

At BMC, research is always in progress.

Learn more biomedcentral.com/submissions 